\title{
Water-in-oil emulsification in a bifurcated tree-like network: flow distribution properties and their impact on the emulsion polydispersity
}

\author{
Peipei Zhou ${ }^{\mathrm{a}}$, Dominique Tarlet ${ }^{\mathrm{b}}$, Yilin Fan ${ }^{\mathrm{b}}$, Xiaofang $\mathrm{Hu}^{\mathrm{a}, 1}$, Lingai Luo ${ }^{\mathrm{b}}$ \\ ${ }^{a}$ School of Mechanical and Automotive Engineering, South China University of \\ Technology (SCUT), Guangzhou, China \\ ${ }^{b}$ Laboratoire de Thermique et Énergie de Nantes (LTEN), CNRS UMR 6607, Université \\ de Nantes, Rue Christian Pauc, BP 50609, 44306 Nantes cedex 3, France
}

\begin{abstract}
This paper presents a numerical study on the water-in-oil emulsification process through the parallelization of micro/mini-channels. Firstly, the single-phase fluid flow distribution uniformity in the bifurcated tree-like fluidic network is discussed. Secondly, the separate roles of the oil viscosity and the interfacial tension on the plug details are clarified. Finally, the impact of flow distribution non-uniformity among the parallel mini-channels on polydispersity of the produced emulsion is evaluated by modelling.

The obtained results show that for bifurcated tree-like fluidic network, the single phase flow distribution is the flow distribution non-uniformity increases linearly with the increasing mean $R e_{c h}$ once a transitional $R e$ is reached. The water plug length and volume increase with the increasing interfacial tension and the decreasing oil viscosity under our tested conditions. Correcting factors relevant to the modified liquid properties have to be added in the predictive correlations for plug length and volume. For water-in-oil emulsification in parallel channels, its polydispersity $P_{w}$ is affected by the single phase flow distribution uniformity, the total water/oil flow-rate ratio and most importantly by the flow-rate ratio distribution non-uniformity. An empirical correlation has been proposed to predict the emulsion $P_{w}$ based on these influencing factors.
\end{abstract}

Email address: scutxiaofang.hu@foxmail.com (Xiaofang $\mathrm{Hu}$ )

${ }^{1}$ corresponding author 
Keywords: Water-oil emulsification; Flow distribution; Monodisperse emulsion; Parallel channels; Bifurcated tree-like 


\section{Nomenclature}

\begin{tabular}{lcc} 
Variable & Meaning & Dimension \\
\hline$d$ & Hydraulic diameter of mini-channel & $\mathrm{m}$ \\
$D_{i}$ & Equivalent diameter of the plug in $i$ mini-channel & $\mathrm{m}$ \\
$D_{w}$ & Average diameter & $\mathrm{m}$ \\
$H$ & Height of the channel & $\mathrm{m}$ \\
$L_{\text {plug }}$ & Length of the generated plug & $\mathrm{m}$ \\
$m$ & Mass flow-rate & $\mathrm{kg} . \mathrm{s}^{-1}$ \\
$\bar{m}$ & Mean mass flow-rate & $\mathrm{kg} \cdot \mathrm{s}^{-1}$ \\
MF & Maldistribution factor & $\%$ \\
mean $R e_{c h}$ & Mean Reynolds number in mini-channel & - \\
$n_{i}$ & Number of the plugs in $i$ mini-channel & - \\
$n_{t o t}$ & Total number of the generated plugs & - \\
$P_{w}$ & Polydispersity & $\%$ \\
$Q$ & Volume flow-rate & $\mathrm{mL} \cdot \mathrm{min}^{-1}$ \\
$R e$ & Reynolds number & - \\
$\bar{u}$ & Mean velocity & $\mathrm{m} . \mathrm{s}^{-1}$ \\
$W$ & Width of the channel & $\mathrm{m}$ \\
$V_{\text {plug }}$ & Volume of the generated plug & $\mathrm{m}$
\end{tabular}




\begin{tabular}{lcc} 
Variable & Meaning & Dimension \\
& Greek symbols & \\
\hline$\gamma_{w / o}$ & Water / oil interfacial tension & $\mathrm{mN.m}^{-1}$ \\
$\mu$ & Dynamic viscosity & Pa.s \\
$\rho$ & Density & $\mathrm{kg} . \mathrm{m}^{-3}$ \\
$\sigma_{w}$ & Standard deviation of all plugs diameter & - \\
$\sigma_{i}$ & Relative deviation of the flow-rate & - \\
\multicolumn{3}{c}{ Subscripts } \\
\hline Exp & Experimental value & \\
$e$ & Emulsion & - \\
$i$ & Number index of channel & - \\
Model & Contactor inlet & - \\
modify & Model & - \\
$o$ & modified oil & - \\
pre & Oil & - \\
pure & Predictive value & - \\
tot & Pure oil & - \\
trans & Total number & - \\
$w$ & Transitional value & -
\end{tabular}




\section{Introduction}

Emulsions play critical roles in the formulation of a wide range of products in various engineering fields including foods, cosmetics, pharmaceuticals, and chemicals. The production of monodisperse emulsions (narrow droplet/plug size distribution) having improved stability and facilitated control of their properties is particularly required, which is of great significance in making microparticles (Takimoto et al. (2015); Zhang et al. (2016)), microcapsules (Amato et al. (2017); Choi et al. (2016)) and in many other microreaction syntheses (Bawazer et al. (2016)).

Over the past two decades, the microfluidic emulsification technique has received a great deal of attention along with the rapid progress in micromachining technology. Compared to conventional emulsification methods involving turbine mixers, colloid mills or homogenizers (Mollet and Grubenmann, 2001), microfluidic emulsification has the ability to generate monodisperse emulsions with the adjustable size and to be coupled with other unit operations in a continuous way, so as to realize a lab-on-a-chip. Abundant literature is available on fundamental emulsification phenomena in a single microchannel. These studies distinguish themselves by the mechanisms of droplets/plugs formation (Garstecki et al. (2006); Steegmans et al. (2009); Nabavi et al. (2017)), by different configurations for liquid-liquid contact (T-junction (Chong et al. (2016); Ma et al. (2017)), cross-junction (Belkadi et al. (2015); Van Loo et al. (2016)), or flow focusing (Josephides and Sajjadi (2015); Du et al. (2018)), by the use of computational fluid dynamics (CFD) (Kashid et al. (2010); Delteil et al. (2011); Chen et al. (2015); Soh et al. (2016); Sontti and Atta (2017)) or experimental approach (Priest et al. (2011); Xi et al. (2016); Teo et al. (2017)), and by different adjustments to achieve highly monodisperse emulsions (Maan et al. (2011); Tanaka et al. (2015); Martins et al. (2017); Akamatsu et al. (2017)). Nevertheless, to overcome the identified barrier of low throughput (or production rate) for a single microchannel, the parallelization of micro/mini-channels is required aiming at industrial-scale mass production.

Relatively fewer studies were devoted to the construction and characterization of liquid-liquid emulsification contactors with parallelized micro/minichannels (Li et al. (2008); Nisisako and Torii (2008); Kobayashi et al. (2010); Romanowsky et al. (2012); Femmer et al. (2015); Schroën et al. (2015); Koppula et al. (2016); Zhou et al. (2017); Stolovicki et al. (2018)). It has been reported that the parallelization of micro/mini-channels may bring some as- 
sociated problems including the reduced emulsion monodispersity (Li et al. (2008); Romanowsky et al. (2012)), higher energy consumption (Nisisako and Torii, 2008) and increased devices complexity. The so-called scalingup by numbering-up process is far from trivial but involves the appropriate connection between macro-scale and micro-scale by using multi-scale fluidic networks (Matlosz et al. (2009); Pistoresi et al. (2018)).

One of the most common types of multi-scale fluidic network is the treelike structure based on dichotomic or tetratomic ramification, which can be subsumed under a more general notion as "vascularization with trees matched canopy to canop" (Lee et al. (2008); Kim et al. (2006)). If properly designed, the bifurcated tree-like structure could provide almost uniform fluid flow distribution among parallel channels under proper operational conditions (Xu et al., 2016). Noteworthy is the contribution of Tesař $(2007,2011)$ on the basic branching hydrodynamics, providing valuable design guidelines for the numbering of microfluidic devices regarding different aimed applications. Recently, a novel parallel minichannel contactor having a bifurcated tree-like structure (as shown in Fig.1) has been proposed and tested by our group. Results obtained in our previous experimental study (Zhou et al. (2017)) showed that for water-pure oil flow, the novel contactor is capable of producing monodisperse water-in-oil emulsions with high throughput and low energy consumption. The impacts of liquid physical properties (e.g., viscosity, interfacial tension) on the emulsion polydispersity have also been discussed.

However, the influence of individual factor (viscosity or interfacial tension) on the droplet/plug length (volume) has not been well clarified via experiments(Zhou et al. (2017)), because the surfactant added in the oil phase modifies simultaneously the surface tension and the viscosity of the working fluids. CFD simulation as a useful tool is thus necessary to be employed, for the purpose of providing additional insights on the droplet/plug generation within emulsification process. Concerning the bifurcated tree-like structure, the actual water and oil flow distribution uniformities among the 16 Y-junctions in parallel have not yet been evaluated in Zhou et al. (2017), mainly due to the experimental measuring difficulties during the optical visualization. Moreover, detailed investigation on the impacts of distribution non-uniformity of each fluid flow-rate and their ratio on the emulsion polydispersity are still lacking in the literature.

This study aims at addressing the above-mentioned issues that have not been tackled in our previous work (Zhou et al. (2017)). The main objec- 
tives and originalities of the paper are then threefold: (1) to propose for the first time a Reynolds number-based correlation for the prediction of single phase flow distribution non-uniformity in the bifurcated tree-like fluidic network; (2) to reveal the separate roles of the viscosity and the interfacial tension on the droplet/plug details, and to proposed modified models for its length and volume prediction; (3) to evaluate the impact of flow distribution non-uniformity on the emulsion polydispersity, a topic with great practical significance from the point view of process intensification, but hasn't been properly adressed yet to the best of our knowledge.

The rest of this paper is organized as follows. In section 2, differen$\mathrm{t}$ methodologies are introduced including a brief description of the $16 \mathrm{Y}$ junction contactor, the geometry and the numerical parameters used. CFD results for single-phase or two-phase flow are presented in section 3.1 and 3.2 , respectively. Modelling results on the relation between emulsion polydispersity and the flow distribution non-uniformity are shown in section 3.3. Section 4 provides further discussions on some interesting issues. Finally, main conclusions and future work are summarized in section 5 .

\section{Methodologies}

\subsection{Device}

The studied parallel mini-channel contactor based on the split-contactrecombine concept is shown in Fig.1(a). Its internal channel structure is composed of three parts: two tree-like fluid distributors for water and for oil, respectively, 16 parallel Y-junctions for water-oil contact and one fluid collector for emulsion collection. The tree-like distributor has four bifurcating generations $\left(2^{4}=16\right)$, so as to divide the fluid fed at the global inlet into 16 small sub-streams (Fig.1(b)). Water-in-oil emulsions are then produced in 16 Y-junctions in parallel. Each Y-junction has a rectangular cross-section (Fig.1(c)) of $1.0 \mathrm{~mm}$ in width $(W)$ and $0.6 \mathrm{~mm}$ in height $(H)$, the hydraulic diameter $(d)$ being $0.75 \mathrm{~mm}$. The angle of intersection between two inlets of the Y-junction is $60^{\circ}$. The endpoints of the $16 \mathrm{Y}$-junctions are connected to the fluid collector having identical tree-like geometry but with opposite flowing direction. Detailed description of the parallel mini-channel contactor and its internal channel dimensions are available in Zhou et al. (2017).

A contactor prototype made of transparent resin (WaterClear Ultra 10122) has been realized using laser stereolithography and tested in laboratory LTEN, France. The test-rig, the measuring instruments and the experimental 


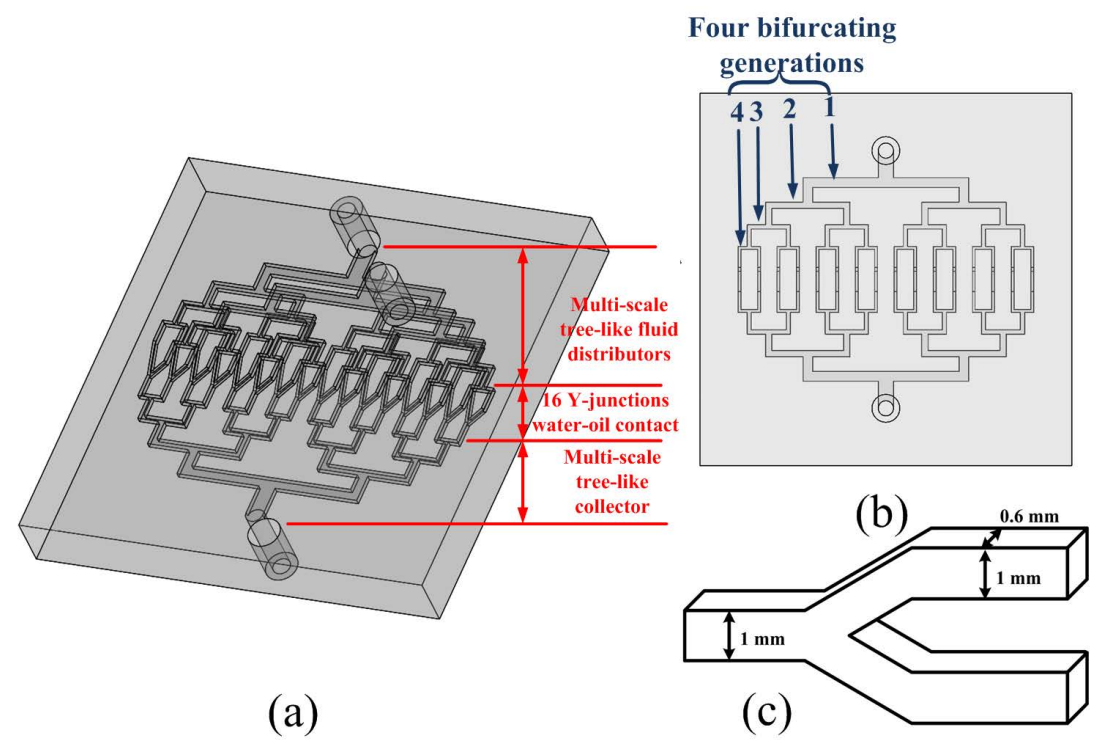

Figure 1: Parallel mini-channel contactor for water-in-oil emulsification. (a) split-contactrecombine concept; (b) top view; (c) zoom on the single Y-junction. Adapted from Zhou et al. (2017).

procedure for water-in-oil emulsification may be found in our earlier study (Zhou et al. (2017)).

\subsection{CFD simulation parameters for single-phase flow}

The purpose of single-phase flow CFD simulation is to evaluate the flow distribution non-uniformity in such bifurcated fluidic network. The model geometry shown in Fig.2(a) is close to a half version of whole device so as to lessen the computation burden owning to the axial symmetry feature. For some high flow-rate cases (e.g., inlet $R e \geq 2000$ ), the global outlet channel was sufficiently lengthened to avoid the reversal back-flow at the outlet surface which may affect the calculation accuracy and the convergence.

The working fluids, including water, pure oil (filtered sunflower oil, carrefour), oil with 5\% Butanol and oil with 13\% Butanol were fed in the inlet port at constant temperatures $\left(22^{\circ} \mathrm{C}\right)$. The physical properties of fluids used in the CFD simulations are listed in Tab.1. For each working fluid, a wide range of mass flow-rate $\left(m_{i n}\right)$ has been tested. The Reynolds number at the global inlet $\left(R e_{i n}\right)$ ranges from 10.7 to 10700 for water and from 0.15 to 153 for pure oil, respectively. The corresponding mean Reynolds number 


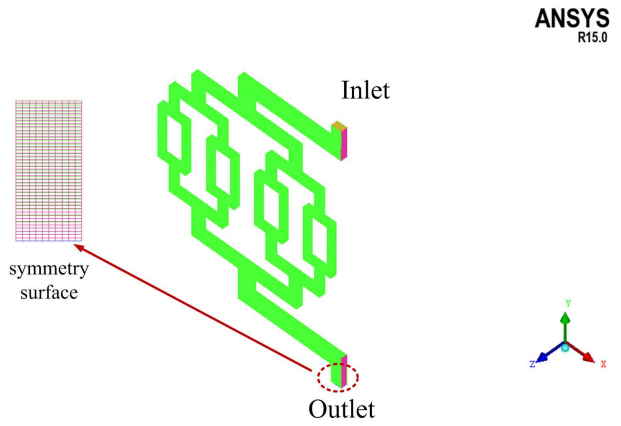

(a)

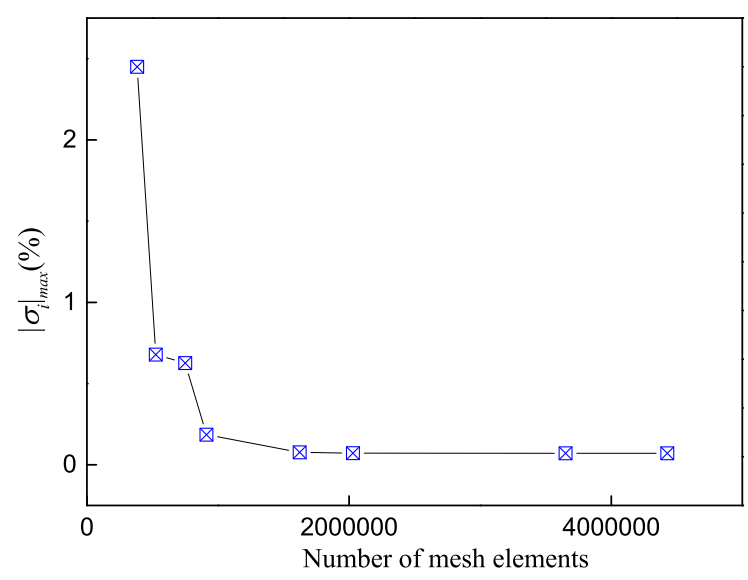

(b)

Figure 2: 3D drawing of the geometry used in CFD simulation for single-phase flow. (a) geometry and grid; (b) grid independence verification. 


\begin{tabular}{lcccc}
\hline Liquids $\left(22{ }^{\circ} \mathrm{C}\right)$ & Water & Pure oil & $5 \%$ Butanol oil & $13 \%$ Butanol oil \\
\hline$\rho\left[\mathrm{g} . \mathrm{L}^{-1}\right]$ & 998 & 865 & 862 & 857 \\
$\mu[\mathrm{mPa} . \mathrm{s}]$ & 0.96 & 58 & 44 & 34 \\
$m_{\text {in }}\left[\mathrm{g} . \mathrm{s}^{-1}\right]$ & $0.0225-22.5$ & $0.0195-19.5$ & $0.0194-19.4$ & $0.0193-19.3$ \\
$R e_{\text {in }}$ & $10.7-10700$ & $0.153-153$ & $0.202-202$ & $0.259-259$ \\
mean $R e_{c h}$ & $1.828-1828$ & $0.026-26$ & $0.034-34$ & $0.044-44$ \\
\hline
\end{tabular}

Table 1: Physical properties of working fluids and tested ranges for single phase flow simulation.

among parallel mini-channels $\left(R e_{c h}\right)$ ranges from 1.8 to 1828 and from 0.026 to 26 , respectively. The operational pressure was fixed at $101325 \mathrm{~Pa}$. In this study, simulations were performed under steady-state, incompressible and isothermal condition without viscous heating or gravity effect.

FLUENT code (version 15.0) was employed to solve Navier-Stokes equations. Laminar flow model was used under very low velocity conditions while the $k-\varepsilon$ RNG model was used for higher velocity conditions due to the presence of micro-turbulence and local vortex at elbows and bifurcations of the tree-like structure. The Coupled scheme was chosen for pressure-velocity coupling and first-order upwind differential scheme was applied for discretization of momentum and standard method for pressure. Constant velocity profile normal to the entry face was given at the inlet port and the boundary condition for the outlet was set as pressure-outlet with zero static pressure. The wall surfaces were set to have no-slip. The solution was considered to be converged when sums of the normalized residuals for control equation were less than $1 \times 10^{-5}$ and the mass flow-rate in each channel was constant from one iteration to the next (less than $1 \%$ variation).

Structured meshes (Fig.2(a)) were generated using ICEM (version 15.0) to build up the geometry model. A grid independence study was performed with the increased number of total elements from 0.4 million to 4.4 million. Figure 2(b) indicates that for a mass flow-rate of water at $2.25 \times 10^{-4} \mathrm{~kg} . \mathrm{s}^{-1}$, the variation of $\left|\sigma_{i}\right|_{\max }$ (as defined in Eq.1) is appreciable with a mesh having more than 1 million elements. This confirms that the current mesh density (1.5 million elements in total, 20 elements for one millimeter) was appropriate.

\subsection{CFD simulation parameters for two-phase flow}

Two-phase flow CFD simulations were also performed to clarify the separate effect of influencing factors on the plug length and volume. The model 
geometry is a single Y-junction having a cross-section of $W=1 \mathrm{~mm}$ and $H=0.6 \mathrm{~mm}$, as shown in Fig.3(a). Water and oil were used as the dispersed phase and the continuous phase, respectively. Physical properties of working fluids used in the simulations and the tested ranges are shown in Tab.2.

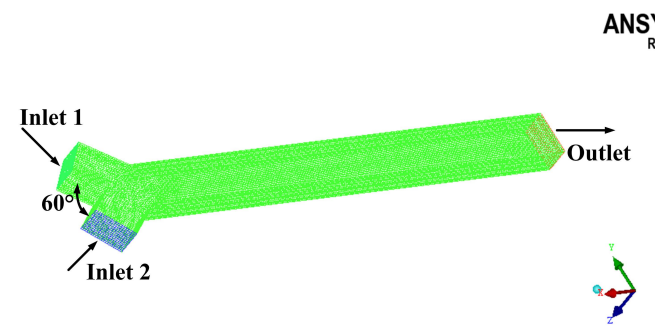

(a)

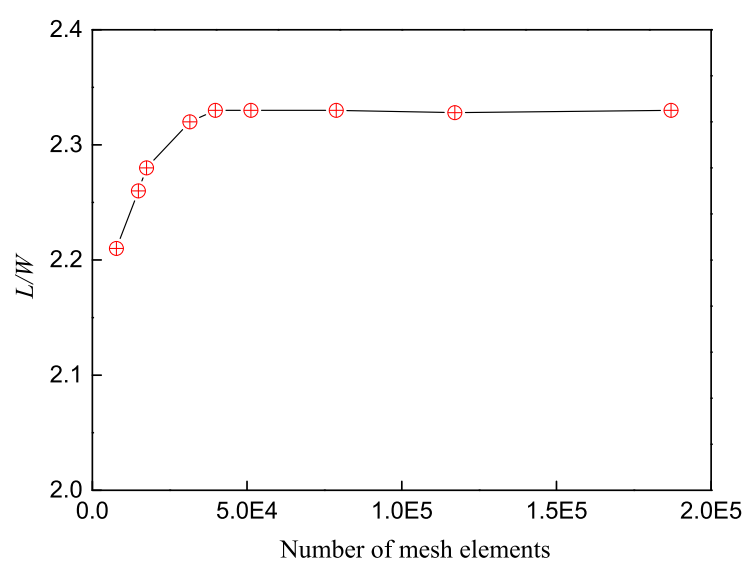

(b)

Figure 3: 3D drawing of the single Y-junction used in CFD simulation for two-phase flow. (a) geometry and grid; (b) grid independence verification.

The plug generation process was simulated by the FLUENT software (version 15.0). Volume of Fluid (VOF) model (Hirt and Nichols, 1981) was used since two fluids (oil and water) are immiscible. In VOF model, different phases are not interpenetrating, but calculated using a single set of momentum equations with different volume fractions of phases in each computational cell. PISO (pressure-implicit with splitting of operators) scheme was used for pressure-velocity coupling, and second-order upwind differencing was applied for discretization of momentum and PRESTO! for pressure. Laminar model was used due to the low $R e$ number $(R e<23)$ under our 


\begin{tabular}{lccccc}
\hline Liquids $\left(22{ }^{\circ} \mathrm{C}\right)$ & Flow rate ratio & $\mu$ & $\gamma_{w / o}$ & $\gamma$ & $\rho$ \\
\hline Water & & $\mathrm{mPa} . \mathrm{s}$ & $\mathrm{mN} . \mathrm{m}^{-1}$ & $\mathrm{mN} . \mathrm{m}^{-1}$ & $\mathrm{~g} . \mathrm{L}^{-1}$ \\
Pure oil & - & 0.96 & - & 73.5 & 998 \\
Oil with 5\% Butanol & $0.125-2$ & 58 & 27.6 & 33.7 & 865 \\
Oil with varied $\mu$ & $0.125-2$ & $24-64$ & 12.8 & - & 862 \\
Oil with varied $\gamma_{w / o}$ & $0.125-2$ & $24-64$ & 27.6 & - & 865 \\
\hline
\end{tabular}

Table 2: Physical properties of working fluids and tested ranges for two-phase flow simulation.

tested conditions for two-phase flow. The courant number was 0.25 for the volume fraction. Constant fluid flow velocity at inlet surface was given and pressure-outlet with zero static pressure was set as the boundary condition of outlet. Simulations were performed under transient state with fixed time step of $4 \times 10^{-4} \mathrm{~s}$. The absolute convergence criterion was set as $10^{-5}$. In this study, a constant contact angle condition is set as $150^{\circ}$ based on the experimental results (Zhou et al. (2017)).

The structured model mesh was generated using ICEM (version15.0). A grid independence study was performed with the increased number of total elements from 12907 to 194046 . Fig.3(b) indicates that the variation in the plug length is negligible when the number of mesh elements is over 70000. Hence, this mesh density (84912 elements in total, 20 elements for one millimeter) was used in this part of study. All simulations were performed on a lenovo G510 workstation which has 2 Intel Core i5-4210M CPU (2.60 $\mathrm{GHz}$ ) and 4 GB RAM. Generally it took about three days for one simulation case.

\section{Results and discussion}

\subsection{Single-phase fluid flow distribution among parallel mini-channels}

CFD simulations have been performed in the tree-like structure shown in (Fig.2(a)) to investigate the single-phase flow distribution uniformity for different fluids under varied flow-rate conditions. In this study, the flow distribution uniformity is quantified by two parameters: the relative flowrate deviation $\left(\sigma_{i}\right)$ and the maldistribution factor (MF), defined as:

$$
\sigma_{i}=\frac{m_{i}-\bar{m}}{\bar{m}} \times 100 \%
$$




$$
\mathrm{MF}=\sqrt{\frac{1}{M-1} \sum_{i=1}^{M}\left(\frac{m_{i}-\bar{m}}{\bar{m}}\right)^{2}} \times 100 \%
$$

Here, $M=16$ is the sampling number of parallel mini-channels and $\bar{m}$ stands for the average value of flow-rate.

$$
\bar{m}=\frac{1}{M} \sum_{i=1}^{M} m_{i}
$$

The mean Reynolds number in the mini-channels (mean $R e_{c h}$ ) which indicates the ratio of inertial force to the viscous force is calculated as:

$$
\text { mean } R e_{c h}=\frac{\rho d \bar{u}}{\mu}=\frac{2 \bar{m}}{(H+W) \mu}
$$

where $\bar{u}$ is the mean velocity magnitude $\left(\mathrm{m} . \mathrm{s}^{-1}\right), \rho$ and $\mu$ are the density $\left(\mathrm{kg} . \mathrm{m}^{-3}\right)$ and the viscosity (mPa.s) of the fluid, respectively. $d$ is the hydraulic diameter of the mini-channel $(0.75 \mathrm{~mm})$.

Figure 4 shows the contour of velocity magnitude of fluid flow (water) in the bifurcated tree-like structure as well as in the cross-section of parallel mini-channels. At relatively low inlet flow-rate $\left(m_{\text {in }}=2.25 \times 10^{-5} \mathrm{~kg} . \mathrm{s}^{-1}\right.$; mean $\left.R e_{c h}=1.828\right)$, the velocity profiles are smooth and regular: higher velocity at the center of the channels while lower velocity at the corners or close to the walls. This is because the viscous force plays a dominant role compared to the inertial force so that the flow pattern tends to become fullydeveloped laminar. At such small inlet flow-rate $\left(R e_{c h}=1.828\right)$, the disturbed velocity profiles due to direction changes at elbows and bifurcations can be shortly recovered so that the downstream branches could receive almost equal amount of fluid flow. The images of cross-sections a1-a8 in Fig.4(a) show similar and symmetric parabolic velocity profiles, indicating that the flow distribution is uniform with very small values of $\left|\sigma_{i}\right|_{\max }(0.074 \%)$ and MF (0.03\%).

When the flow-rate of fed liquid increases $\left(m_{\text {in }}=2.25 \times 10^{-2} \mathrm{~kg} . \mathrm{s}^{-1}\right.$; mean $R e_{c h}=1828$ ), the effects of singular losses at numerous bifurcations and elbows become significant, indicated by the appearance of detached flows, stagnant zones as well as the noticeable local vortex and micro-turbulences at 


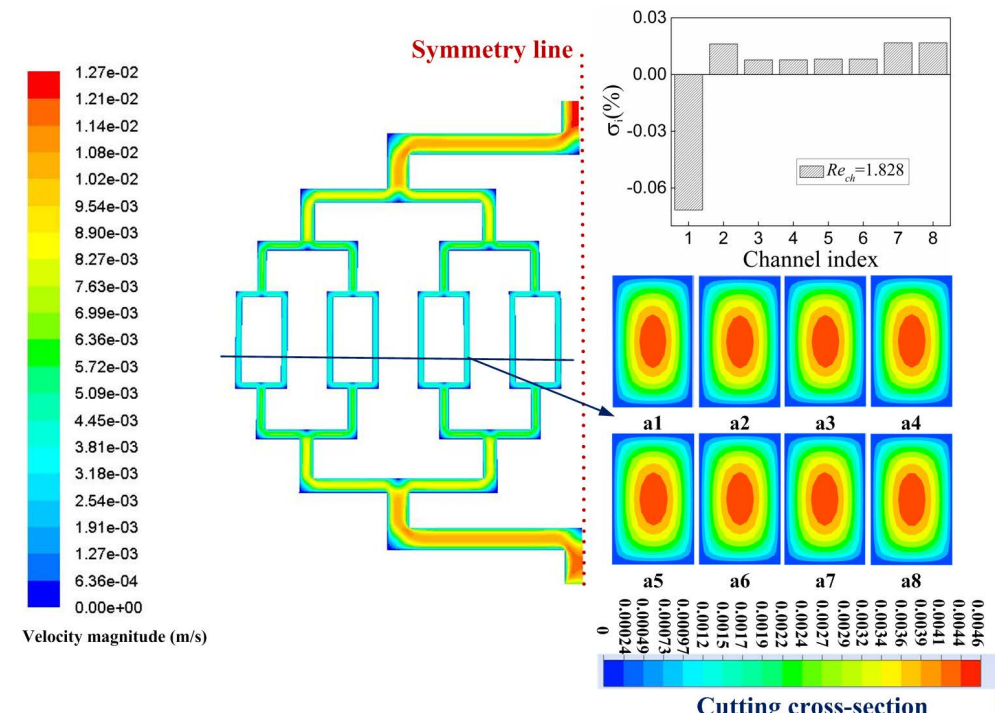

(a)

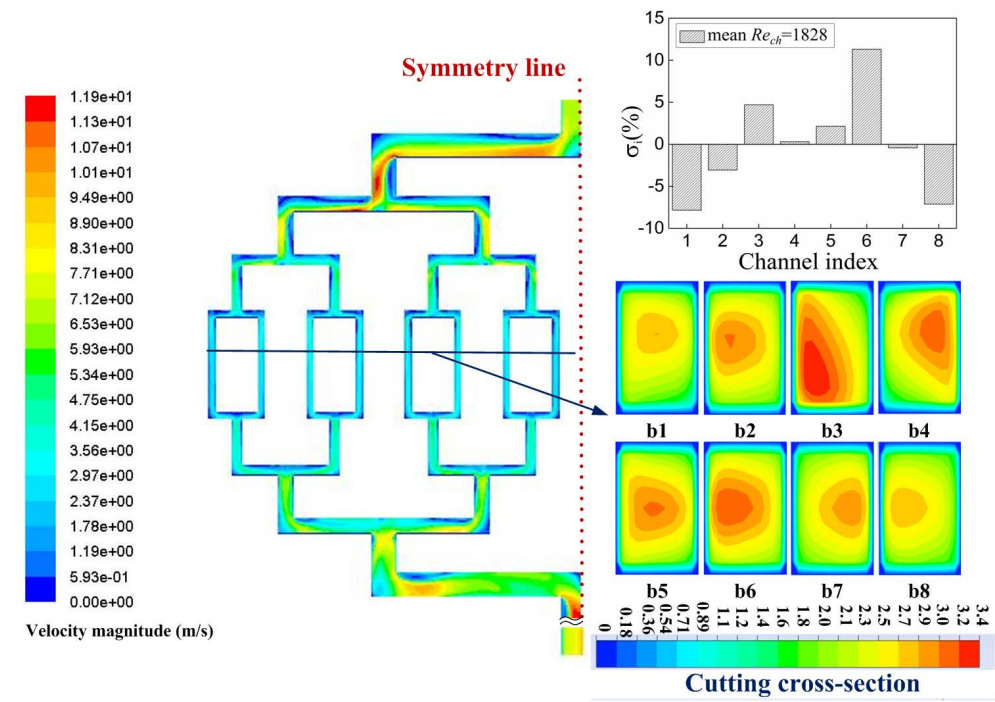

(b)

Figure 4: Contour of velocity magnitude of water flow in the bifurcated tree-like structure and in the cutting cross-sections of parallel mini-channels. (a) $m_{i n}=2.25 \times 10^{-5} \mathrm{~kg} . \mathrm{s}^{-1}$; mean $R e_{c h}=1.828$; (b) $m_{\text {in }}=2.25 \times 10^{-2} \mathrm{~kg} \cdot \mathrm{s}^{-1}$; mean $R e_{c h}=1828$. 
various locations. Moreover, velocity profiles at the downstream branches of a bifurcation are no longer symmetrical due to the stronger inertial forces. This imbalanced flow-rate division may accumulate after successive bifurcations, implying a certain degree of flow distribution non-uniformity among the 16 parallel mini-channels $\left(\left|\sigma_{i}\right|_{\max }=11.3 \% ; \mathrm{MF}=6.2 \%\right)$. As shown by the crosssectional images b1-b8 in Fig.4(b), the flow patterns are clearly not fullydeveloped compared to the symmetrical parabolic velocity profiles in a1-a8.

The higher flow distribution non-uniformity at high flow-rates in the bifurcated structures has been observed in our earlier studies (Fan et al. (2008); Guo et al. (2014)), in line with other relevant works in this area (Liu and Li (2013); Liu et al. (2010); Mu et al. (2015); Tesař (2011)).

But we intend to make a step further. Some interesting trends may then be revealed by plotting the fluid flow distribution non-uniformity $\left(\left|\sigma_{i}\right|_{\max }\right.$; MF values) as a function of the mean $R e_{c h}$ for different working fluids, as shown in Fig.5. For mean $R e_{c h}$ below 12, the values of $\left|\sigma_{i}\right|_{\max }$ and MF are small and constant (Eq.5), implying that the flow distribution is uniform and independent of the mean $R e_{c h}$. This is because disturbed velocity profiles can be recovered within a short distance at low mean $R e_{c h}$ so that equal flow-rate division may be perfectly achieved at each bifurcation. The zero-approaching values of $\left|\sigma_{i}\right|_{\max }$ and MF may only arise from the computational inaccuracy.

$$
\begin{aligned}
\left|\sigma_{i}\right|_{\text {max }}(\%) & =0.074 \\
\operatorname{MF}(\%) & =0.03 \quad \text { for mean } R e_{c h}<12
\end{aligned}
$$

For mean $R e_{c h}>12$, both $\left|\sigma_{i}\right|_{\max }$ and MF values of different fluids depend only on the mean $R e_{c h}$ regardless of the fluid nature. This is because the density and the viscosity of fluid have already been taken into account in the nondimensional Reynolds number. The flow distribution non-uniformity grows linearly with increasing mean $R e_{c h}$, as shown in Fig.5. This is because the inertial force becomes stronger at higher mean $R e_{c h}$ and its impact is also more significant. The departure from the fully symmetric flow profile upstream of each bifurcation results in the non-equal flow-rate division to two downstream branches (as shown in Fig.4(b)).

$$
\begin{aligned}
\left|\sigma_{i}\right|_{\text {max }}(\%) & =0.0062 \times \text { mean } R e_{c h} \\
\operatorname{MF}(\%) & =0.0036 \times \text { mean } R e_{c h} \quad \text { for mean } R e_{c h}>12
\end{aligned}
$$


Eq.6 proposes a linear correlation for predicting the flow distribution non-uniformity. It may be observed that the predicted results are generally in good agreement with the obtained numerical results, with $12 \%$ and $9.6 \%$ MAPE (mean absolute percentage error) for $\left|\sigma_{i}\right|_{\text {max }}$ and for MF, respectively. MAPE is used to estimate the deviation between the measured $\left(M_{i}\right)$ and predicted value $\left(P_{i}\right)$, as explained by Eq.7 (Kim et al. (2014)).

$$
\operatorname{MAPE}(\%)=\frac{1}{N} \sum_{i=1}^{N}\left|100 \times \frac{M_{i}-P_{i}}{M_{i}}\right|
$$

The value of mean $R e_{c h}=12$ determined in this study may be considered as a transitional Reynolds number $\left(R e_{\text {trans }}\right)$ below which the inertial force has no influence on the flow distribution uniformity. When the real mean $R e_{c h}$ is higher than the $R e_{\text {trans }}$, the flow distribution non-uniformity increases linearly with the increasing mean $R e_{c h}$. The value of $R e_{\text {trans }}$ may differ from one study to another, depending on the geometry (number of bifurcations, number of parallel channels, etc.) and dimensions (length, hydraulic diameter of channels, etc.) of the bifurcated tree-like structure. Once the value of $R e_{\text {trans }}$ is determined for a certain bifurcated tree-like structure, the flow distribution uniformity at a given flow-rate can then be evaluated using the correlations such as proposed in Eqs.5 and 6. The existence of transitional Reynolds number has been reported by other researchers (Delsman et al. (2004); Griffini and Gavriilidis (2007)), but specifically for Z-type ladder fluidic networks rather than for bifurcated tree-like structures.

Finally one may observe that under our tested conditions (mean $R e_{c h}$ up to 1828), the flow distribution non-uniformity is kept at a low level $\left(\left|\sigma_{i}\right|_{\max } \leq\right.$ $12 \% ; \mathrm{MF} \leq 6.5 \%)$. These results show relatively uniform single-phase flow distribution among parallel mini-channels.

\subsection{Influencing factors on the droplet/plug generation}

Typical droplets/plugs formation in the single Y-junction has been successfully simulated using the VOF model. Figure 6 depicts a confrontation on the droplet/plug shape simulated by CFD in this study and previously captured experimentally by fast camera (Zhou et al. (2017)) under the same water and oil flow-rates conditions. It can be observed that the lengths of droplets/plugs and their intervals are generally in good agreement. Quanti- 


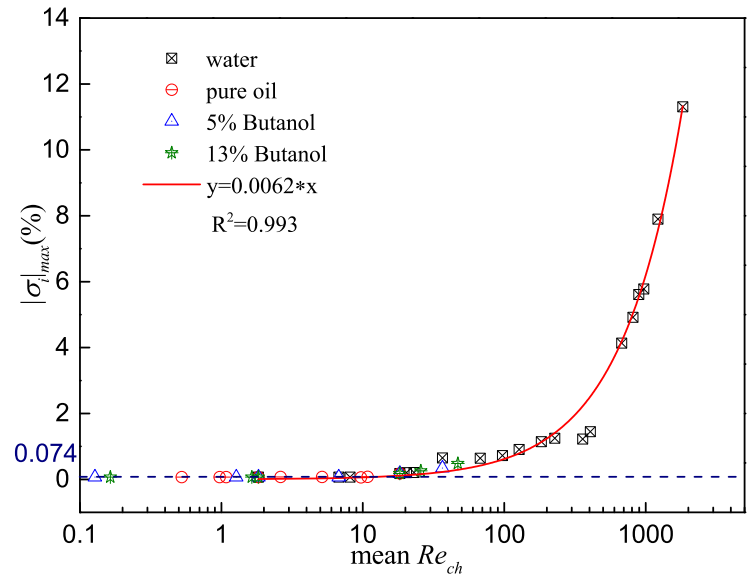

(a)

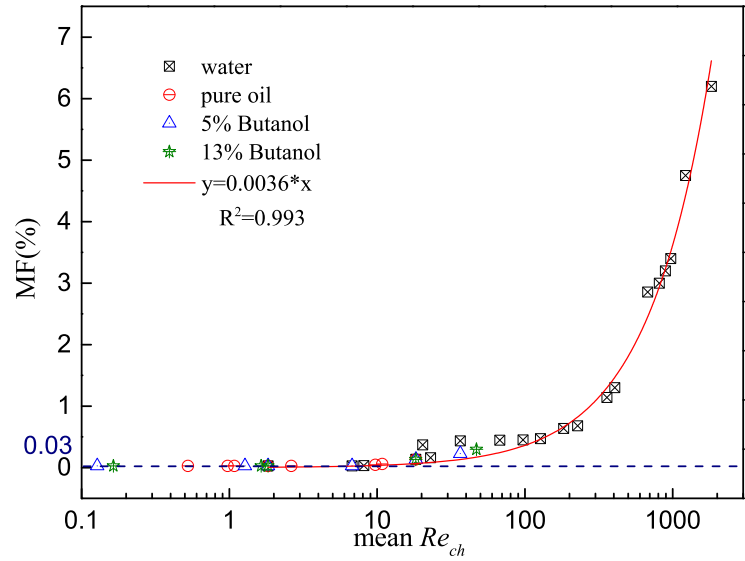

(b)

Figure 5: Simulation results and fitting curves for $\left|\sigma_{i}\right|_{\max }$ (a) and for MF (b). 
tative comparison on the plug length between numerical and experimental results will be reported later.

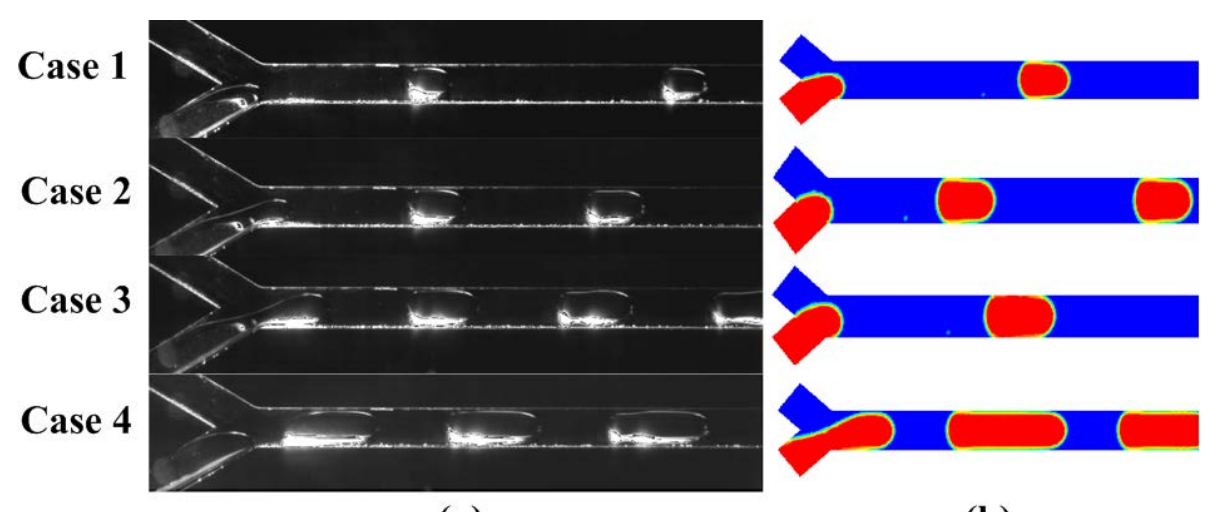

(a)

(b)

Figure 6: Comparison on the droplet/plug generation between experiments (a) (Zhou

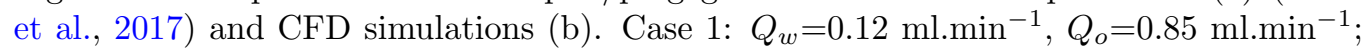
Case 2: $Q_{w}=0.2 \mathrm{ml} \cdot \mathrm{min}^{-1}, Q_{o}=0.38 \mathrm{ml} \cdot \mathrm{min}^{-1}$; Case 3: $Q_{w}=0.05 \mathrm{ml} \cdot \mathrm{min}^{-1}, Q_{o}=0.1$ ml.min ${ }^{-1}$; Case 4: $Q_{w}=0.45 \mathrm{ml} \cdot \mathrm{min}^{-1}, Q_{o}=0.3 \mathrm{ml} \cdot \mathrm{min}^{-1}$.

The effect of interfacial tension $\left(\gamma_{w / o}\right)$ on the plug length and volume is shown in Fig.7 with water-oil flow-rate ratio $\left(Q_{w} / Q_{o}\right)$ of $0.25,0.5$ and 1 . At a certain $Q_{w} / Q_{o}$, the plug length and volume generally increase when interfacial tension rises from $11.8 \mathrm{mN} . \mathrm{m}^{-1}$ to $60 \mathrm{mN} \cdot \mathrm{m}^{-1}$. This is because the interfacial tension is the only conservative force to hinder separation of the plug from the dispersed phase (Bashir et al. (2011)). Therefore, the balance of force is easier to be broken at low interfacial tension, resulting in faster plug formation and smaller plug length (volume). CFD results also reveal the relatively small variation of plug length (volume) when $\gamma_{w / o}$ value is larger than $40 \mathrm{mN} \cdot \mathrm{m}^{-1}$.

Figure 8 shows the effect of oil viscosity on the plug length and volume under different interfacial tension conditions. The length and volume of water plugs obtained in high viscous oil are smaller than those in low viscous oil. Earlier breakup happens when the oil viscosity rises, because the adhesion force is more prominent than the shear force during the detachment of plugs (Tice et al. (2004)). Nevertheless, the variation is relatively smaller within the tested $\mu_{o}$ range. The same trend has also been observed in our previous experimental work (Zhou et al. (2017)).

Figure 9 shows that the plug length $\left(L_{\text {plug }}\right)$ and volume $\left(V_{\text {plug }}\right)$ increase when $Q_{w} / Q_{o}$ ratio rises for both water-pure oil flow $\left(\gamma_{w / o}=27.6 \mathrm{mN} \mathrm{m}^{-1}\right)$ 


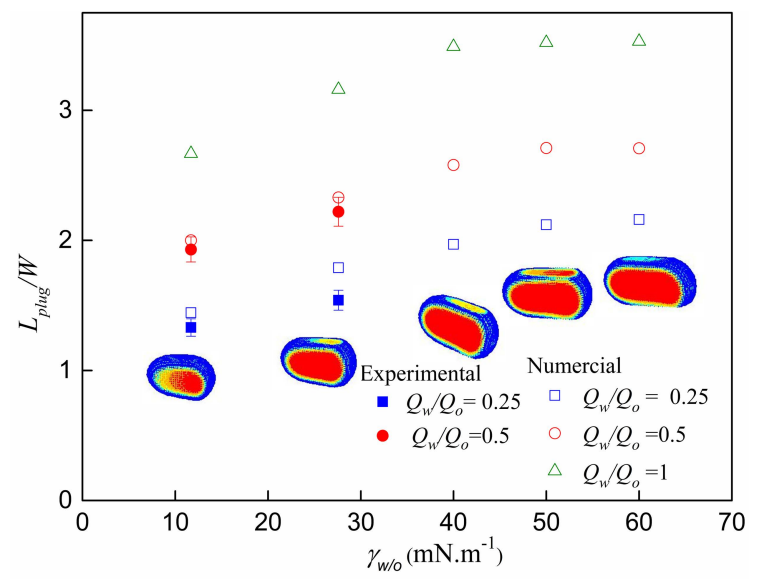

(a)

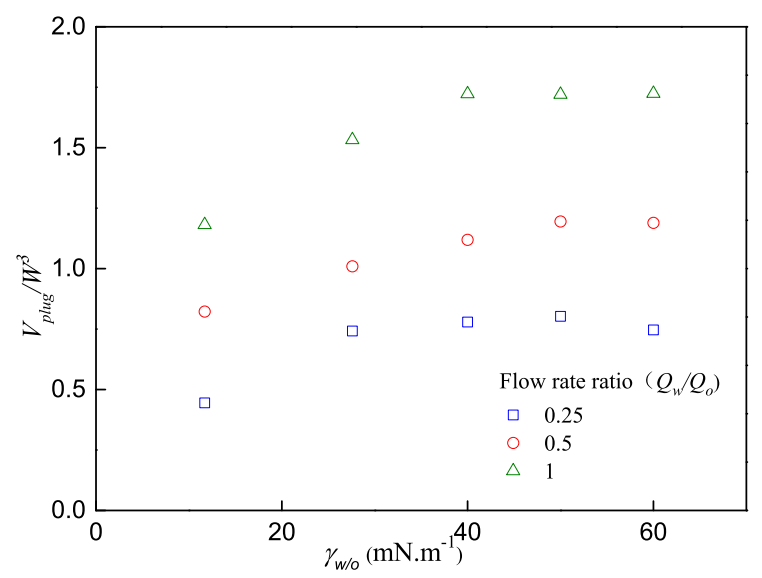

(b)

Figure 7: Effect of surface tension on the plug length (a) and the volume (b) under different water-oil flow-rate ratios. $Q_{w}=0.084 \mathrm{ml} . \mathrm{min}^{-1} ; \mu_{o}=58 \mathrm{mPa} . \mathrm{s}$. 


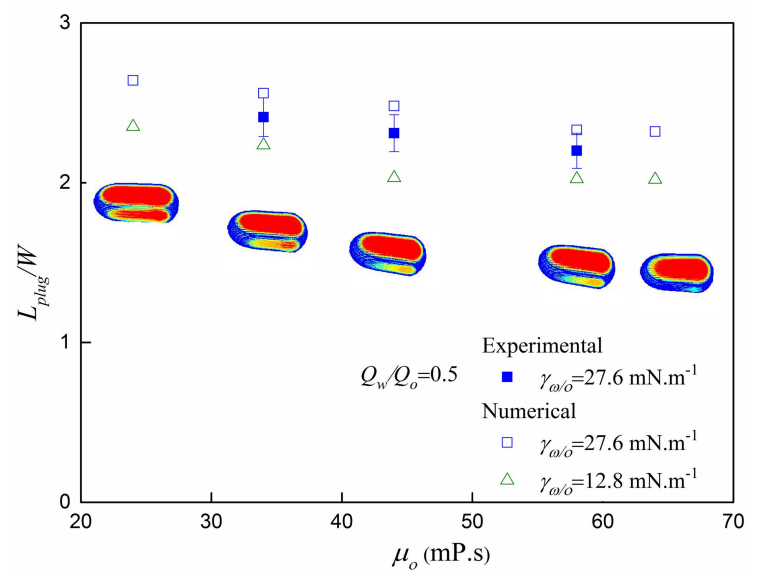

(a)

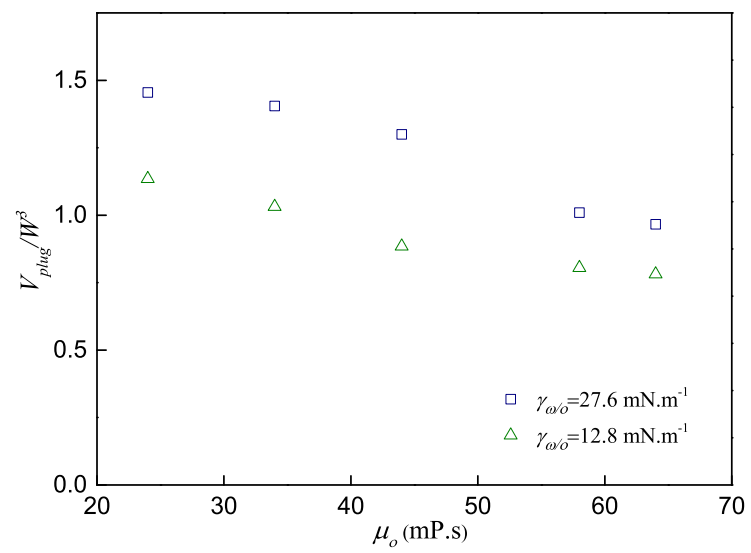

(b)

Figure 8: Effect of oil viscosity on the droplet/plug length (a) and volume (b) with interfacial tension $\left(\gamma_{w / o}\right)$ of $27.6 \mathrm{mN} . \mathrm{m}^{-1}$ and $12.8 \mathrm{mN}^{-1} \mathrm{~m}^{-1}\left(Q_{w} / Q_{o}=0.5\right)$. 
and water-oil with $0.3 \% \operatorname{SPAN}\left(\gamma_{w / o}=11.7 \mathrm{mN}^{-1}\right)$. For water-pure oil flow, the correlation (Eq.8) fitted for the numerical results is really close to the one reported in Zhou et al. (2017), indicating very good agreement $(\mathrm{MAPE}=1.5 \%)$. Eq.9 presents the fitted correlation for $V_{\text {plug }}$, which will be used in the following sub-section to calculate the emulsion polydispersity.

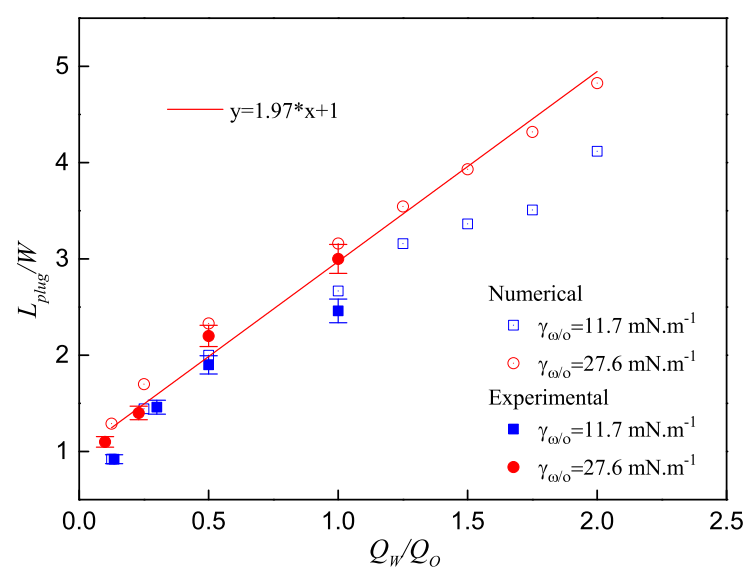

(a)

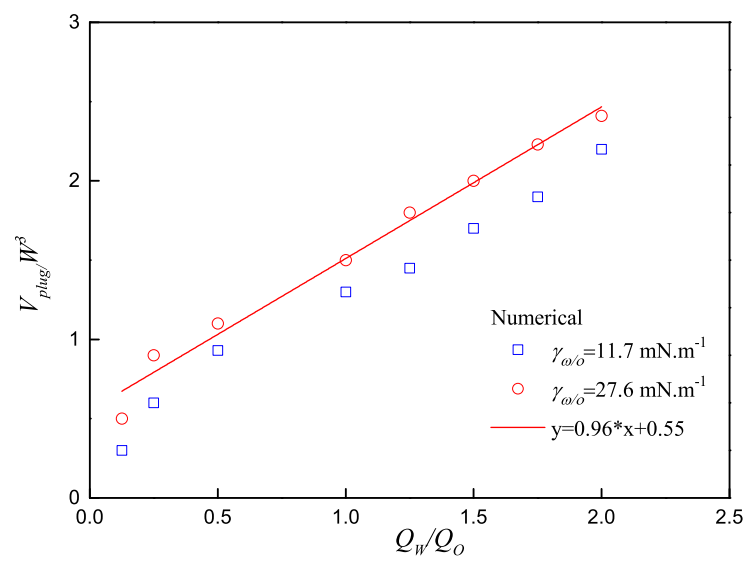

(b)

Figure 9: Effect of flow-rate ratio on the plug length (a) and volume (b) with interfacial tension $\left(\gamma_{w / o}\right)$ of $27.6 \mathrm{mN} \cdot \mathrm{m}^{-1}$ and $11.7 \mathrm{mN} \cdot \mathrm{m}^{-1}$.

$$
\frac{L_{p l u g}}{W}=1.97\left(\frac{Q_{w}}{Q_{o}}\right)+1
$$




$$
\frac{V_{p l u g}}{W^{3}}=0.96\left(\frac{Q_{w}}{Q_{o}}\right)+0.55
$$

For water-oil flow with modified interfacial tension or oil viscosity, it is necessary to add some correcting factors in the correlated equations 8 and 9. Therefore, Equations 10 and 11 are proposed based on the numerical data to predict the plug length and volume, respectively, by adding two correcting factors $\left(\frac{\mu_{o, \text { modify }}}{\mu_{o, \text { pure }}}\right)$ and $\left(\frac{\gamma_{w / o, \text { modify }}}{\gamma_{w / o, \text { pure }}}\right)$. Satisfactory agreement between the predicted results and numerical data can be obtained (MAPE $=9.6 \%$ for plug length and MAPE $=9.2 \%$ for plug volume).

$$
\begin{gathered}
\frac{L_{\text {plug }}}{W}=\left(\frac{\mu_{o, \text { modify }}}{\mu_{o, \text { pure }}}\right)^{-0.4} \cdot\left(\frac{\gamma_{w / o, \text { modify }}}{\gamma_{w / o, \text { pure }}}\right)^{0.22} \cdot\left[1.97\left(\frac{Q_{w}}{Q_{o}}\right)+1\right] \\
\frac{V_{\text {plug }}}{W^{3}}=\left(\frac{\mu_{o, \text { modify }}}{\mu_{o, \text { pure }}}\right)^{-0.27} \cdot\left(\frac{\gamma_{o, \text { modify }}}{\gamma_{o, \text { pure }}}\right)^{0.15} \cdot\left[0.96\left(\frac{Q_{w}}{Q_{o}}\right)+0.55\right]
\end{gathered}
$$

\subsection{Influence of flow distribution non-uniformity on the emulsion polydis- persity}

The flow distribution non-uniformity of oil and water among the parallel mini-channels may lead to the varied water-in-oil flow-rate ratio $\left(Q_{w} / Q_{o}\right)$ that determines the length (volume) of generated plugs/droplets. In this case, the emulsion monodispersity reached within a single mini-channel may no longer be maintained after the numbering-up process. In this section, we will try to evaluate the impact of flow distribution non-uniformity on the emulsion monodispersity, which is of practical significance from the point of view of process intensification.

For simplicity reason, the 16 parallel mini-channel contactor is taken as example, using water and pure oil as the working fluids. For the water plugs generated in one mini-channel $i$, their equivalent diameter $D_{i}$ may be calculated as the diameter of sphere having identical volume:

$$
V_{\text {plug }, i}=\frac{\pi D_{i}^{3}}{6}
$$

By introducing the previously obtained correlation (Eq.9) for the plug volume (water-pure oil flow) in a single Y-junction into Eq.12, $D_{i}$ can be expressed as: 


$$
D_{i}=\sqrt[3]{\frac{6 V_{\text {plug }, i}}{\pi}}=\sqrt[3]{\frac{6\left(0.96\left(Q_{w, i} / Q_{o, i}\right)+0.55\right) W^{3}}{\pi}}
$$

Here, $Q_{w, i}$ and $Q_{o, i}$ are the volume flow-rate of water and oil in the minichannel $i$, respectively. According to the mass conservation, the total flow-rate of water or oil is the sum of 16 channel flow-rates.

$$
Q_{w, t o t}=\sum_{i=1}^{16} Q_{w, i} \quad Q_{o, t o t}=\sum_{i=1}^{16} Q_{o, i}
$$

The number of water plugs generated in minichannel $i$ per unit time can be calculated as:

$$
n_{i}=\frac{Q_{w, i}}{V_{\text {plug }, i}}
$$

The total number of plugs/droplets in 16 parallel parallel mini-channels per unit time and the average diameter $\left(D_{w}\right)$ can be written as:

$$
\begin{gathered}
n_{\text {tot }}=\sum_{i=1}^{16} n_{i} \\
D_{w}=\frac{\sum_{i=1}^{16} D_{i} n_{i}}{n_{\text {tot }}}
\end{gathered}
$$

The emulsion polydispersity $P_{w}$ is defined as the ratio of the standard deviation $\left(\sigma_{w}\right)$ of all $\left(n_{t o t} \geq 1000\right)$ plugs diameter and the average diameter $\left(D_{w}\right)$, written as:

$$
P_{w}=\frac{\sigma_{w}}{D_{w}}
$$

Different influencing factors on the emulsion polydispersity are systematically studied and their impacts are evaluated. The tested factors include the single-phase flow distribution non-uniformity $\left(\mathrm{MF}_{w}, \mathrm{MF}_{o}\right)$, water/oil flowrate ratio distribution non-uniformity $\left(\mathrm{MF}_{w / o}\right)$ and the total flow-rate ratio $\left(Q_{w, t o t} / Q_{o, t o t}\right) . \quad \mathrm{MF}_{w}$ and $\mathrm{MF}_{o}$ have already been defined in Eq.2 (simply substituting mass flow-rate $m_{i}$ by volume flow-rate $Q_{i}$ ). Flow-rate ratio nonuniformity $\left(\mathrm{MF}_{w / o}\right)$ is defined in Eq.19:

$$
\mathrm{MF}_{w / o}=\sqrt{\frac{1}{15} \sum_{i=1}^{16}\left(\frac{\frac{Q_{w, i}}{Q_{o, i}}-\frac{\overline{Q_{w, i}}}{Q_{o, i}}}{\frac{\overline{Q_{w, i}}}{Q_{o, i}}}\right)^{2}} \times 100 \%
$$


where $\frac{\overline{Q_{w, i}}}{Q_{o, i}}$ is the mean value of all water/oil flow-rate ratios among 16 parallel minichannels.

$$
\frac{\overline{Q_{w, i}}}{Q_{o, i}}=\frac{1}{16} \sum_{i=1}^{16} \frac{Q_{w, i}}{Q_{o, i}}
$$

For each modelling, $Q_{w, i}$ and $Q_{o, i}$ are firstly imposed for minichannel $i$, and the equivalent diameter $\left(D_{i}\right)$ and number $\left(n_{i}\right)$ of the generated water plugs per unit time can be calculated following Eq.13 and Eq.15. Then the obtained data for every individual mini-channel are convoluted together so as to calculate the global $P_{w}$ of 16 parallel mini-channels.

The impact of single-phase MF on the emulsion polydispersity is shown in Fig.10, when one fluid distribution is preset as uniform while the other is not (the shape of distribution curve is shown in the top-left corner of Fig.10). The total flow-rate of water and oil are kept the same $\left(Q_{w, t o t}=1.35 \mathrm{ml} \cdot \mathrm{min}^{-1}\right.$; $\left.Q_{o, t o t}=2.88 \mathrm{ml} . \mathrm{min}^{-1}\right)$ while $\mathrm{MF}_{w}$ varies between $0.03 \%$ and $30 \%\left(\mathrm{MF}_{o}=0\right)$, or vice versa $\left(\mathrm{MF}_{w}=0\right)$. It may be observed that the $P_{w}$ value increases almost linearly with the increasing $\mathrm{MF}_{w}$ or $\mathrm{MF}_{o}$, and their effects are almost the same. In order to produce monodispersed water-in-oil emulsions (e.g., $P_{w}<4 \%$ ), the theoretical MF value of one fluid should be smaller than about $25 \%$ when the flow distribution of another fluid is uniform.

Shown in Fig.11 is the impact of two-phase MF on the emulsion polydispersity when both $\mathrm{MF}_{w}$ and $\mathrm{MF}_{o}$ vary from $0.03 \%$ to $30 \%\left(\mathrm{MF}_{w}=\mathrm{MF}_{o}\right)$ but the value of $\mathrm{MF}_{w / o}$ (as defined in Eq.19) varies from 0.06 to 60\%. The schematic shape of both distribution curves is shown in the top-left corner of Fig.11, the total flow-rate of water and oil being the same $\left(Q_{w, t o t}=1.35\right.$ ml.min $\left.{ }^{-1} ; Q_{o, t o t}=2.88 \mathrm{ml} . \mathrm{min}^{-1}\right)$. It may be observed that the $P_{w}$ value rises linearly with the increasing $\mathrm{MF}_{w / o}$. One may also observe that large $\mathrm{MF}_{w}$ and $\mathrm{MF}_{o}$ with small $\mathrm{MF}_{w / o}$ still render low $P_{w}$ values. This is because in our model, the plug equivalent diameter $D_{i}$ is only determined by the water/oil flow-rate ratio (Eq.13). In order to obtain monodisperse emulsions, the single-phase flow distribution could be both non-uniform, but the variation of flow-rate ratio among parallel channels should be maintained as small as possible.

Figure 12 indicates the impact of total flow-rate ratio $\left(Q_{w, t o t} / Q_{o, t o t}\right)$ on the emulsion polydispersity. The total water flow-rate $\left(Q_{w, t o t}\right)$ is $1.35 \mathrm{ml} \cdot \mathrm{min}^{-1}$, distributed uniformly among the 16 parallel mini-channels. For pure oil, the total flow-rate $\left(Q_{o, t o t}\right)$ varies between $0.74 \mathrm{ml} . \mathrm{min}^{-1}$ and $11.4 \mathrm{ml} . \mathrm{min}^{-1}$, with 


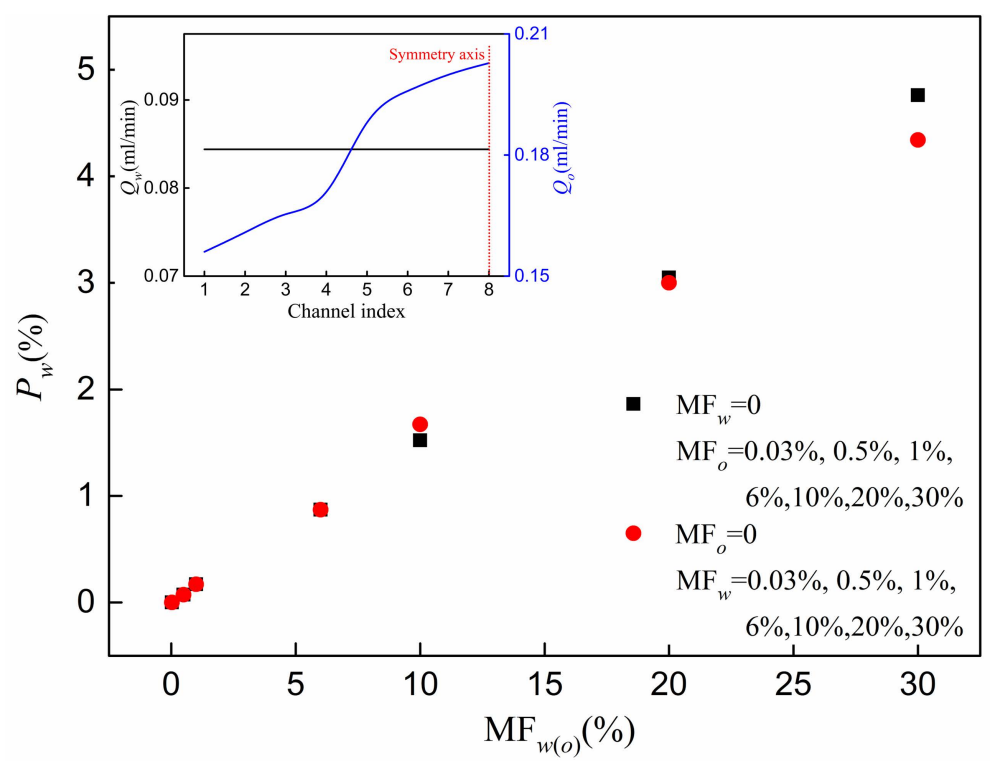

Figure 10: Impact of single-phase MF on the emulsion polydispersity $\left(Q_{w, t o t}=1.35\right.$ ml.min $\left.{ }^{-1} ; Q_{o, t o t}=2.88 \mathrm{ml} \cdot \mathrm{min}^{-1}\right)$.

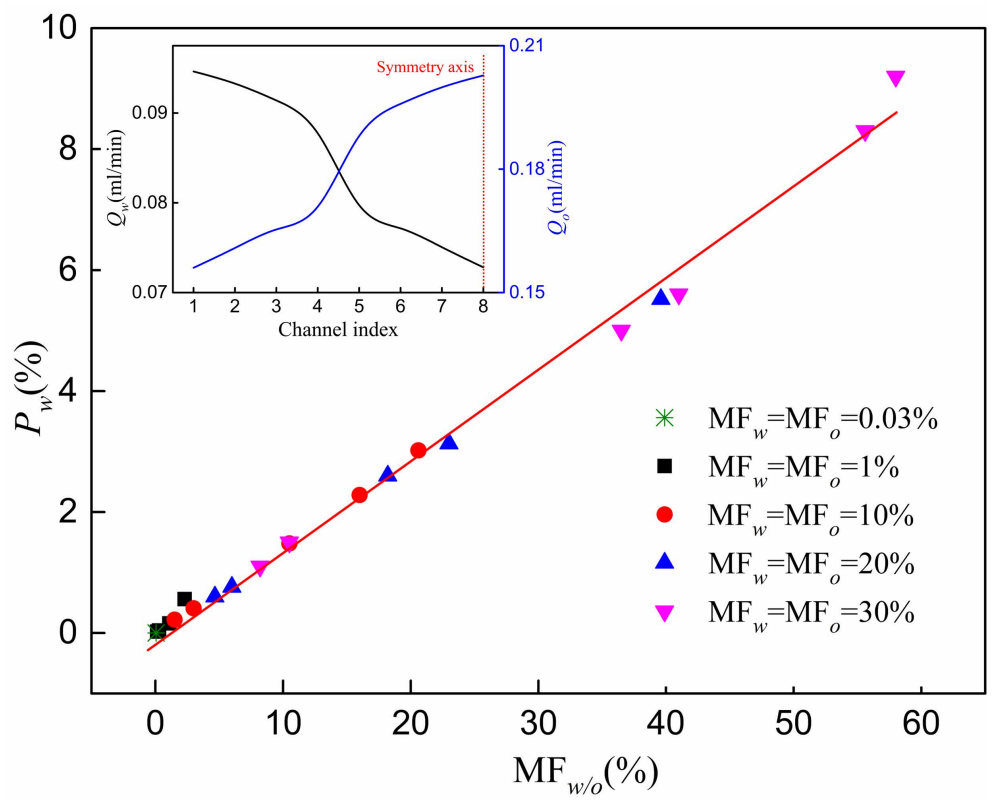

Figure 11: Impact of two-phase MF on the emulsion polydispersity $\left(Q_{w, t o t}=1.35 \mathrm{ml} \cdot \mathrm{min}^{-1}\right.$; $\left.Q_{o, t o t}=2.88 \mathrm{ml} \cdot \mathrm{min}^{-1}\right)$. 
$\mathrm{MF}_{o}$ value being $10 \%, 20 \%$ and $30 \%$. It may be observed that $P_{w}$ increases when $Q_{w, t o t} / Q_{o, t o t}$ rises. The intrinsic reason is that higher $Q_{w, t o t} / Q_{o, t o t}$, results in large $\mathrm{MF}_{w / o}$, even though the values of $\mathrm{MF}_{w}$ and $\mathrm{MF}_{o}$ are kept unchanged.

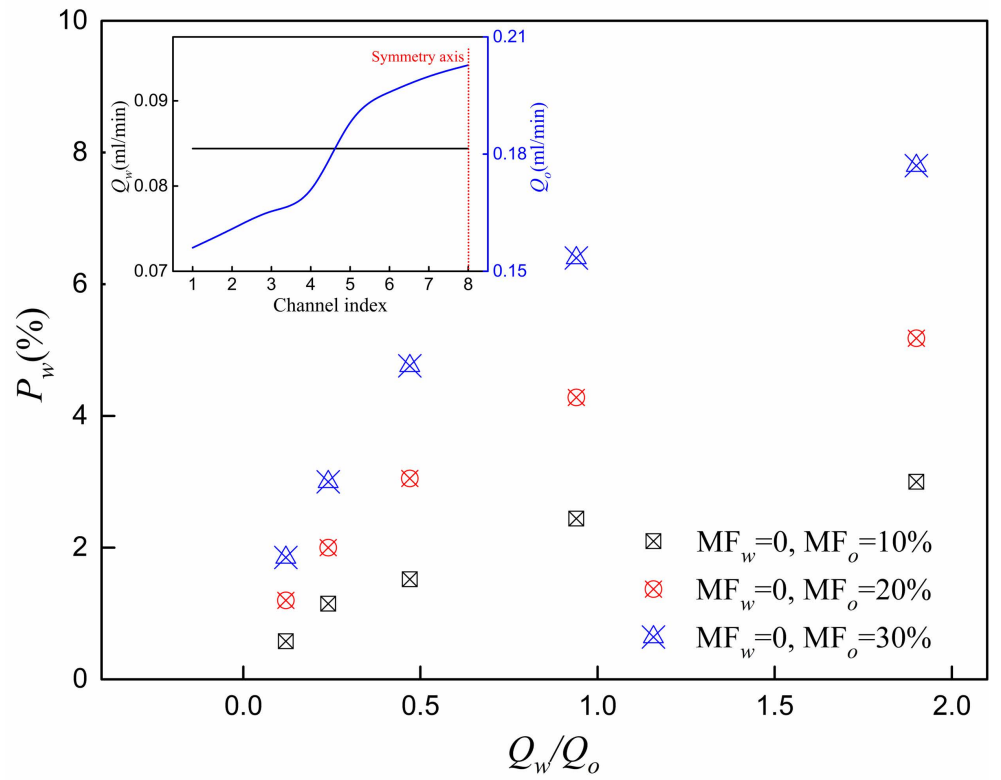

Figure 12: Impact of total flow-rate ratios on the emulsion polydispersity $\left(Q_{w, t o t}=1.35\right.$ ml.min $\left.{ }^{-1} ; Q_{o, t o t}=0.74,1.35,2.88,5.7,11.4 \mathrm{ml} \cdot \mathrm{min}^{-1}\right)$; the insert represents the case of $Q_{o, t o t}=2.88 \mathrm{ml} \cdot \mathrm{min}^{-1}\left(\mathrm{MF}_{o}=10 \%\right)$

The modeling results presented above indicate that for parallel channels water-in-oil emulsification, its polydispersity $P_{w}$ is affected by the liquid distribution $\left(\mathrm{MF}_{w}\right.$ and $\left.\mathrm{MF}_{o}\right)$, the total flow-rate ratios $\left(Q_{w, t o t} / Q_{o, t o t}\right)$ and most importantly by the flow-rate ratio distribution $\left(\mathrm{MF}_{w / o}\right)$. An empirical correlation is then proposed as Eq.21 to predict the emulsion $P_{w}$, taking these influencing factors into account.

$$
P_{w}(\%)=0.16\left(\mathrm{MF}_{w}+\mathrm{MF}_{o}\right)^{0.07}\left(\frac{Q_{w, t o t}}{Q_{o, t o t}}\right)^{0.44} \mathrm{MF}_{w / o}
$$

For a certain emulsion operation with fixed $Q_{w, t o t}$ and $Q_{o, t o t}$, the $P_{w}$ is mainly determined by $\mathrm{MF}_{w / o}$, following the liner correlation in Fig.11. Figure 13 shows that the predicted $P_{w}$ is in good agreement with the obtained modelling data, with a MAPE of $8 \%$. 


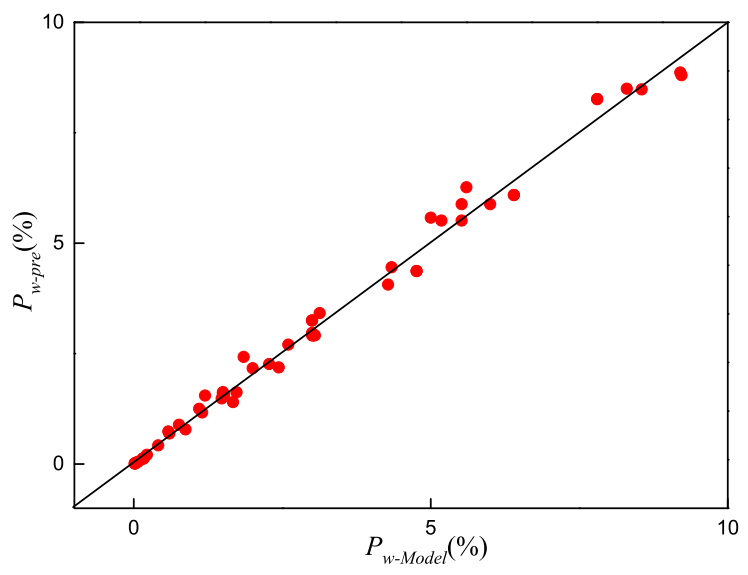

Figure 13: Predicted $P_{w}$ by Eq.21 compared with modeling $P_{w}$ data for parallel channels emulsification.

\section{Further discussions}

- $P_{w-M o d e l}$ VS. $P_{w-E x p}$

For tested flow-rates (mean $R e_{c h}<2$ ) in our experimental study (Zhou et al. (2017)), it has been shown in Eq.5 that the flow distribution of oil and water among parallel mini-channels is uniform $(\mathrm{MF}=0.03 \%)$. The $P_{w}$ values calculated by modeling $\left(P_{w-\text { Model }}\right)$ are also very low $(0.0003 \%)$, indicating the mass production of highly monodisperse waterin-oil emulsions after parallelization. The performance is better than that experimentally measured $\left(3.04 \%<P_{w-E x p}<4.53 \%\right)$ using the same 16 mini-channels contactor under the same conditions, even better than that within a single Y-junction $\left(1.25 \%<P_{w-s}<2.14 \%\right.$ ) (Zhou et al. (2017)).

Apart from the various measurement uncertainties and casualties (liquid flow-rate instability, flowmeter uncertainty, image treatment error, etc.) in real-world engineering, following reasons may be responsible for the higher emulsion polydispersity measured in experiments than calculated by modelling. Firstly, the manufacturing tolerance may cause small differences in the size of channels and the surface roughness variation of the internal walls. These will result in large difference in pressure drop in milli or microfluidic devices and associated passage-to-passage flow non-uniformity (Jeon et al. (2000)). Secondly, interactions and collisions of water droplets may occur at the multiple converging points 
of the multi-scale tree-like collector, implying the droplets deformation and the change of volumes. Finally, the flow distribution of water or oil is evaluated to be uniform only for single-phase flow. For two-phase flow through the tree-like distributors, a certain degree of non-uniformity may still appear among the parallel Y-junctions because of the pressure interactions between two fluids. This will again cause different flow-rate ratios, leading to augmented $P_{w}$ values.

- Bifurcated tree-like structure for uniform flow distribution: pros \& cons

Successful parallelization of mini-channels is realized by using bifurcated tree-like structure, generating highly monodisperse water-in-oil emulsions. This is partially because the bifurcated tree-like structure fits well the working conditions of this emulsification process, under which a relatively uniform flow distribution among parallel channels/tubes can be guaranteed. Nevertheless, it also has its scope of application, preferentially for small mean $R e_{c h}$ as has been shown in Eqs.5 and 6 . The inevitable higher distribution non-uniformity at high flowrates due to increasing impact of inertial forces is an intrinsic character of such bifurcated tree-like structure. A slight asymmetry velocity profile at one bifurcation would lead to large non-uniformity after successive bifurcations. Moreover, it is highly likely that the $R e_{\text {trans }}$ may be much smaller (e.g., <1) for some more complicated geometries involving merging branches and flow remixing, such as those used in Jeon et al. (2000).

In brief, bifurcated tree-like structure is an effective and practical concept for process intensification through successful numbering-up. But it should be used with caution, especially when high throughputs are involved. Tesař (2011) concluded that nominally isokinetic designs of the branching geometry may not guarantee the uniform flow distribution, and some accelerating non-isokinetic layouts could be a more favorable choice. Liu and $\mathrm{Li}$ (2013) reported that for such bifurcated structure, the length of channel from the elbow to the branching point plays a decisive role in equal flow-rate division. Nevertheless, a longer length (or larger length to diameter ratio) is needed to develop a symmetric velocity profile at higher flow-rate, implying lower compactness. Sometimes a choice (or a compromise) should be made among throughput (productivity), geometry (compactness) and distri- 
bution uniformity (product quality). Developing predictive models for single-phase flow distribution non-uniformity that fits more general bifurcated geometries and operational conditions for engineering practice is one direction of our future work.

- Correlation between emulsion polydispersity $\left(P_{w}\right)$ and MF for more general conditions

In this study, the working fluid couple used is water and pure oil, for the modelling of emulsion polydispersity within a 16 mini-channel contactor. The obtained correlation Eq.21 reveals the relation between emulsion polydispersity and the flow distribution uniformity of working fluids and it can be easily extended to more general conditions. For the oil phase with modified physical properties, Eq.11 may be used to substitute Eq.9 in Eq.13. The following convolution procedure remains unchanged. For other emulsification working couples (Span or Butanol), the most delicate part of the exercise is actually to obtain the expression for $V_{\text {plug }, i}$, using experimental or numerical approaches.

Moreover, the extension of the correlation to $M$ parallel channels conditions is also straightforward, through the different calculation of certain parameters. Due to the limited length of the article, the superfluous modelling procedure will not be detailed here.

\section{- VOF model VS. CLSVOF model}

VOF model is used in this study to simulate the water droplet/plug generation process in a single $\mathrm{Y}$-junction. The numerical results obtained are generally consistent with the experimental results (Fig.9(a)), but discrepancy still exists especially for $Q_{w} / Q_{i} \geq 1$. Insufficient mesh density and inaccuracy of VOF model may be responsible for this discrepancy.

Besides the VOF model, other methods are available to capture the interface between two immiscible fluids such as Level Set (LS), Front Tracking, Phase Field and Lattice Boltzmann (Wörner, 2012). In the study of Dang et al. (2015) for the simulation of Taylor bubble formation in a microchannel, it was reported that compared with VOF method, the coupled Level Set and VOF (CLSVOF) method can yield a more accurate gas-liquid interface especially at the rupture stage of the emerging bubble. The CLSVOF model may then be applied for 
the more accurate simulation of droplet/plug formation in water-in-oil emulsification. This is one direction of our following work.

\section{Conclusion and perspectives}

This work studies the intensification of water-in-oil emulsification process through the parallelization of micro/mini-channels. In particular, the fluid flow distribution properties in the bifurcated tree-like fluidic network and their impact on the emulsion polydispersity are systematically investigated. Based on the results and discussions presented above, the following conclusions can be drawn.

(1) The existence of transitional Reynolds number $\left(R e_{\text {trans }}\right)$ has been observed for the bifurcated tree-like fluidic network. For mean $R e_{c h}<$ $R e_{\text {trans }}$, the single phase flow distribution is uniform and stable (Eq.5). For mean $R e_{c h}>R e_{\text {trans }}$, the flow distribution non-uniformity increases linearly with the increasing mean $R e_{c h}$ (Eq.6).

(2) The water plug length and volume increase with the increasing interfacial tension $\left(11.8 \mathrm{mN} . \mathrm{m}^{-1}-60 \mathrm{mN} . \mathrm{m}^{-1}\right)$ and the decreasing oil viscosity (64 mPa.s 24 mPa.s). Modified correlations (Eqs.10, 11) have been proposed to predict the plug length and volume based on the water/oil flow-rate ratio and the correcting factors for modified liquid properties (with respect to pure oil).

(3) For parallel channels water-in-oil emulsification, its polydispersity $P_{w}$ is affected by the single phase flow distribution uniformity $\left(\mathrm{MF}_{w}\right.$ and $\left.\mathrm{MF}_{o}\right)$, the total flow-rate ratio $\left(Q_{w, t o t} / Q_{o, t o t}\right)$ and most importantly by the flow-rate ratio distribution $\left(\mathrm{MF}_{w / o}\right)$. An empirical correlation has been proposed as Eq.21 to predict the emulsion $P_{w}$ based on these influencing factors.

One part of our current work is focused on the development and implementation of adequate numerical or experimental methods for characterizing the entire 16 Y-junctions contactor, in order to gain detailed information on the two-phase flow distribution properties. Moreover, the industrial application of such contactor is also our on-going work to illustrate the emulsification intensification achieved by parallelization concept and by managed fluid distribution. Finally, producing monodisperse emulsions is not the unique requirement while for some other processes such as micro-explosion 
of fuels (Tarlet et al. (2009, 2014)), the heterogeneity of droplets/plugs size distribution is specifically aimed. The bifurcated tree-like network seems to be incapable of providing such heterogeneity and some other flow distribution management methods (e.g., geometrically optimized baffle method (Wei et al. $(2015,2016))$ may be more adapted for such applications.

\section{Acknowledgments}

The authors gratefully acknowledge the support of China Scholarship Council (CSC).

\section{References}

Akamatsu, K., Minezaki, K., Yamada, M., Seki, M., Nakao, S.-i., 2017. Direct observation of splitting in oil-in-water-in-oil emulsion droplets via a microchannel mimicking membrane pores. Langmuir.

Amato, D. V., Lee, H., Werner, J. G., Weitz, D. A., Patton, D. L., 2017. Functional microcapsules via thiol-ene photopolymerization in dropletbased microfluidics. ACS applied materials \& interfaces 9 (4), 3288-3293.

Bashir, S., Rees, J. M., Zimmerman, W. B., 2011. Simulations of microfluidic droplet formation using the two-phase level set method. Chemical Engineering Science 66 (20), 4733-4741.

Bawazer, L. A., McNally, C. S., Empson, C. J., Marchant, W. J., Comyn, T. P., Niu, X., Cho, S., McPherson, M. J., Binks, B. P., Meldrum, F. C., et al., 2016. Combinatorial microfluidic droplet engineering for biomimetic material synthesis. Science advances 2 (10), e1600567.

Belkadi, A., Tarlet, D., Montillet, A., Bellettre, J., Massoli, P., 2015. Water-in-oil emulsification in a microfluidic impinging flow at high capillary numbers. International Journal of Multiphase Flow 72, 11 - 23.

URL http://www.sciencedirect.com/science/article/pii/ S0301932215000178

Chen, B., Li, G., Wang, W., Wang, P., 2015. 3d numerical simulation of droplet passive breakup in a micro-channel t-junction using the volumeof-fluid method. Applied Thermal Engineering 88, 94-101. 
Choi, C.-H., Lee, H., Abbaspourrad, A., Kim, J. H., Fan, J., Caggioni, M., Wesner, C., Zhu, T., Weitz, D. A., 2016. Triple emulsion drops with an ultrathin water layer: High encapsulation efficiency and enhanced cargo retention in microcapsules. Advanced Materials 28 (17), 3340-3344.

Chong, Z. Z., Tan, S. H., Gañán-Calvo, A. M., Tor, S. B., Loh, N. H., Nguyen, N.-T., 2016. Active droplet generation in microfluidics. Lab on a Chip 16 (1), 35-58.

Dang, M., Yue, J., Chen, G., 2015. Numerical simulation of taylor bubble formation in a microchannel with a converging shape mixing junction. Chemical Engineering Journal 262 (1), 616-627.

Delsman, E., Pierik, A., Croon, M. D., Kramer, G., Schouten, J., 2004. Microchannel plate geometry optimization for even flow distribution at high flow rates. Chemical Engineering Research and Design 82 (2), 267 273, iSMR3-CCRE18.

URL http://www.sciencedirect.com/science/article/pii/ S0263876204724867

Delteil, J., Vincent, S., Erriguible, A., Subra-Paternault, P., 2011. Numerical investigations in rayleigh breakup of round liquid jets with vof methods. Computers and Fluids 50 (1), 10-23.

Du, W., Fu, T., Duan, Y., Zhu, C., Ma, Y., Li, H. Z., 2018. Breakup dynamics for droplet formation in shear-thinning fluids in a flow-focusing device. Chemical Engineering Science 176, 66-76.

Fan, Y., Boichot, R., Goldin, T., Luo, L., 2008. Flow distribution property of the constructal distributor and heat transfer intensification in a mini heat exchanger. AIChE journal 54 (11), 2796-2808.

Femmer, T., Jans, A., Eswein, R., Anwar, N., Moeller, M., Wessling, M., Kuehne, A. J. C., 2015. High-throughput generation of emulsions and microgels in parallelized microfluidic drop-makers prepared by rapid prototyping. Acs Appl Mater Interfaces 7 (23), 12635-12638.

Garstecki, P., Fuerstman, M. J., Stone, H. A., Whitesides, G. M., 2006. Formation of droplets and bubbles in a microfluidic t-junctionscaling and mechanism of break-up. Lab on a Chip 6 (3), 437-446. 
Griffini, G., Gavriilidis, A., 2007. Effect of microchannel plate design on fluid flow uniformity at low flow rates. Chemical Engineering and Technology $30(3), 395-406$.

Guo, X., Fan, Y., Luo, L., 2014. Multi-channel heat exchanger-reactor using arborescent distributors: A characterization study of fluid distribution, heat exchange performance and exothermic reaction. Energy 69 (5), 728 741 .

Hirt, C. W., Nichols, B. D., 1981. Volume of fluid (vof) method for the dynamics of free boundaries. Journal of computational physics 39 (1), 201225 .

Jeon, N. L., Dertinger, S. K. W., Chiu, D. T., Choi, I. S., And, A. D. S., Whitesides, G. M., 2000. Generation of solution and surface gradients using microfluidic systems. Langmuir 16 (22), 8311-8316.

Josephides, D. N., Sajjadi, S., 2015. Increased drop formation frequency via reduction of surfactant interactions in flow-focusing microfluidic devices. Langmuir 31 (3), 1218-1224.

Kashid, M. N., Renken, A., Kiwi-Minsker, L., 2010. Cfd modelling of liquidliquid multiphase microstructured reactor: Slug flow generation. Chemical Engineering Research and Design 88 (3), 362-368.

Kim, N.and Murphy, M. C., Soper, S. A., Nikitopoulos, D. E., 2014. Liquid liquid segmented flows in polycarbonate microchannels with cross-sectional expansions. International Journal of Multiphase Flow 58, 83-96.

Kim, S., Lorente, S., Bejan, A., 2006. Vascularized materials: tree-shaped flow architectures matched canopy to canopy. Journal of Applied Physics 100 (6), 063525.

Kobayashi, I., Wada, Y., Uemura, K., Nakajima, M., 2010. Microchannel emulsification for mass production of uniform fine droplets: integration of microchannel arrays on a chip. Microfluidics and Nanofluidics 8 (2), 255262.

URL http://dx.doi.org/10.1007/s10404-009-0501-y 
Koppula, K. S., Fan, R., Veerapalli, K. R., Wan, J., 2016. Integrated microfluidic system with simultaneous emulsion generation and concentration. Journal of colloid and interface science 466, 162-167.

Lee, J., Kim, S., Lorente, S., Bejan, A., 2008. Vascularization with trees matched canopy to canopy: diagonal channels with multiple sizes. International Journal of Heat and Mass Transfer 51 (7), 2029-2040.

Li, W., Young, E. W., Seo, M., Nie, Z., Garstecki, P., Simmons, C. A., Kumacheva, E., 2008. Simultaneous generation of droplets with differen$\mathrm{t}$ dimensions in parallel integrated microfluidic droplet generators. Soft matter 4 (2), 258-262.

Liu, H., Li, P., 2013. Even distribution/dividing of single-phase fluids by symmetric bifurcation of flow channels. International Journal of Heat and Fluid Flow 40, 165-179.

Liu, H., Li, P., Van Lew, J., 2010. Cfd study on flow distribution uniformity in fuel distributors having multiple structural bifurcations of flow channels. international journal of hydrogen energy 35 (17), 9186-9198.

Ma, R., Fu, T., Zhang, Q., Zhu, C., Ma, Y., Li, H. Z., 2017. Breakup dynamics of ferrofluid droplet in a microfluidic t-junction. Journal of Industrial and Engineering Chemistry 54, 408-420.

Maan, A. A., Schroën, K., Boom, R., 2011. Spontaneous droplet formation techniques for monodisperse emulsions preparation-perspectives for food applications. Journal of food engineering 107 (3), 334-346.

Martins, E., Poncelet, D., Marquis, M., Davy, J., Renard, D., 2017. Monodisperse core-shell alginate (micro)-capsules with oil core generated from droplets millifluidic. Food Hydrocolloids 63, 447-456.

Matlosz, M., Falk, L., Commenge, J.-M., 2009. Structured multi-scale process systems design and engineering-the role of microreactor technology in chemical process design. Micro Process Engineering: A Comprehensive Handbook, Volume 1, 2 and 3,1-21.

Mollet, H., Grubenmann, A., 2001. Formulation technology. Formulation technology. 
Mu, Y.-T., Chen, L., He, Y.-L., Tao, W.-Q., 2015. Numerical study on temperature uniformity in a novel mini-channel heat sink with different flow field configurations. International Journal of Heat and Mass Transfer 85, $147-157$.

Nabavi, S. A., Vladisavljević, G. T., Manović, V., 2017. Mechanisms and control of single-step microfluidic generation of multi-core double emulsion droplets. Chemical Engineering Journal 322, 140-148.

Nisisako, T., Torii, T., 2008. Microfluidic large-scale integration on a chip for mass production of monodisperse droplets and particles. Lab on a Chip 8 (2), 287-293.

Pistoresi, C., Fan, Y., Aubril, J., Luo, L., 2018. Fluid flow characteristics of a multi-scale fluidic network. Chemical Engineering and Processing: Process Intensification 123, 67-81.

Priest, C., Reid, M. D., Whitby, C. P., 2011. Formation and stability of nanoparticle-stabilised oil-in-water emulsions in a microfluidic chip. Journal of colloid and interface science 363 (1), 301-306.

Romanowsky, M. B., Abate, A. R., Rotem, A., Holtze, C., Weitz, D. A., 2012. High throughput production of single core double emulsions in a parallelized microfluidic device. Lab on a Chip 12 (4), 802-807.

Schroën, K., Bliznyuk, O., Muijlwijk, K., Sahin, S., Berton-Carabin, C. C., 2015. Microfluidic emulsification devices: from micrometer insights to large-scale food emulsion production. Current Opinion in Food Science $3,33-40$.

Soh, G. Y., Yeoh, G. H., Timchenko, V., 2016. Numerical investigation on the velocity fields during droplet formation in a microfluidic t-junction. Chemical Engineering Science 139, 99-108.

Sontti, S. G., Atta, A., 2017. Cfd analysis of microfluidic droplet formation in non-newtonian liquid. Chemical Engineering Journal 330, 245-261.

Steegmans, M. L., Schroën, K. G., Boom, R. M., 2009. Characterization of emulsification at flat microchannel y junctions. Langmuir 25 (6), 33963401. 
Stolovicki, E., Ziblat, R., Weitz, D. A., 2018. Throughput enhancement of parallel step emulsifier devices by shear-free and efficient nozzle clearance. Lab on a Chip.

Takimoto, K., Takano, E., Kitayama, Y., Takeuchi, T., 2015. Synthesis of monodispersed submillimeter-sized molecularly imprinted particles selective for human serum albumin using inverse suspension polymerization in water-in-oil emulsion prepared using microfluidics. Langmuir 31 (17), 4981-4987.

Tanaka, H., Yamamoto, S., Nakamura, A., Nakashoji, Y., Okura, N., Nakamoto, N., Tsukagoshi, K., Hashimoto, M., 2015. Hands-off preparation of monodisperse emulsion droplets using a poly(dimethylsiloxane) microfluidic chip for droplet digital pcr. Analytical Chemistry 87 (8), 4134.

Tarlet, D., Bellettre, J., Tazerout, M., Rahmouni, C., 2009. Prediction of micro-explosion delay of emulsified fuel droplets. International Journal of Thermal Sciences 48 (2), 449-460.

Tarlet, D., Mura, E., Josset, C., Bellettre, J., Allouis, C., Massoli, P., 2014. Distribution of thermal energy of child-droplets issued from an optimal micro-explosion. International Journal of Heat and Mass Transfer 77 (4), 1043-1054.

Teo, A. J., Li, K.-H. H., Nguyen, N.-T., Guo, W., Heere, N., Xi, H.-D., Tsao, C.-W., Li, W., Tan, S. H., 2017. Negative pressure induced droplet generation in a microfluidic flow-focusing device. Analytical Chemistry 89 (8), $4387-4391$.

Tesař, V., 2007. Pressure-Driven Microfluidics.

Tesař, V., 2011. Bifurcating channels supplying numbered-up microreactors. Chemical Engineering Research and design 89 (12), 2507-2520.

Tice, J. D., Lyon, A. D., Ismagilov, R. F., 2004. Effects of viscosity on droplet formation and mixing in microfluidic channels. Analytica chimica acta 507 (1), 73-77.

Van Loo, S., Stoukatch, S., Kraft, M., Gilet, T., 2016. Droplet formation by squeezing in a microfluidic cross-junction. Microfluidics and Nanofluidics $20(10), 146$. 
Wei, M., Boutin, G., Fan, Y., Luo, L., 2016. Numerical and experimental investigation on the realization of target flow distribution among parallel mini-channels. Chemical Engineering Research and Design 113, 74-84.

Wei, M., Fan, Y., Luo, L., Flamant, G., 2015. Cfd-based evolutionary algorithm for the realization of target fluid flow distribution among parallel channels. Chemical Engineering Research and Design 100, 341-352.

Wörner, M., 2012. Numerical modeling of multiphase flows in microfluidics and micro process engineering: a review of methods and applications. Microfluidics and Nanofluidics 12 (6), 841-886.

Xi, H.-D., Guo, W., Leniart, M., Chong, Z. Z., Tan, S. H., 2016. Ac electric field induced droplet deformation in a microfluidic t-junction. Lab on a Chip 16 (16), 2982-2986.

Xu, P., Sasmito, A. P., Yu, B., Mujumdar, A. S., 2016. Transport phenomena and properties in treelike networks. Applied Mechanics Reviews 68 (4), 040802.

Zhang, M., Wang, W., Xie, R., Ju, X., Liu, Z., Jiang, L., Chen, Q., Chu, L., 2016. Controllable microfluidic strategies for fabricating microparticles using emulsions as templates. Particuology 24, 18-31.

Zhou, P., Tarlet, D., Wei, M., Fan, Y., Luo, L., 2017. Novel multi-scale parallel mini-channel contactor for monodisperse water-in-oil emulsification. Chemical Engineering Research and Design 121, 233-244. 